\title{
Drastic enhancement of carbon dioxide adsorption in fluoroalkyl-modified poly(allylamine)
}

Athanasios Koutsianos, ${ }^{\mathrm{a}, \dagger}$ Louise B. Hamdy, ${ }^{\mathrm{a}}$ Chun-Jae Yoo, ${ }^{\mathrm{b}}$ Jason J. Lee, ${ }^{\mathrm{b}}$ Marco Taddei,, a, Jagoda M. Urban-Klaehn, ${ }^{\mathrm{c}}$ Jerzy Dryzek, ${ }^{\mathrm{d}}$ Christopher W. Jones, ${ }^{\mathrm{b}}$ Andrew R. Barron, ${ }^{\mathrm{a}, \mathrm{e}, \mathrm{f}}$ and Enrico Andreoli ${ }^{a *}$

${ }^{a}$ Energy Safety Research Institute, Swansea University, Bay Campus, Swansea, SA1 8EN, UK

${ }^{\mathrm{b}}$ School of Chemical \& Biomolecular Engineering, Georgia Institute of Technology, Atlanta, GA 30332, USA

${ }^{\mathrm{c}}$ Energy and Environment S\&T, Idaho National Laboratory, Idaho Falls, ID 83415, USA

${ }^{\mathrm{d}}$ Institute of Nuclear Physics Polish Academy of Sciences, PL-31342 Krakow, Poland

e Department of Chemistry and Department of Materials Science and Nanoengineering, Rice University, Houston, TX 77005, USA

${ }^{\mathrm{f}}$ Faculty of Engineering, Universiti Teknologi Brunei, Brunei Darussalam

$\uparrow$ Current address: Department of Chemistry and Chemical Biology, TU Dortmund, 44227 Dortmund, Germany

+ Current address: Department of Chemistry and Industrial Chemistry, University of Pisa, Pisa 56124, Italy

*e.andreoli@swansea.ac.uk; +44(0)1792602524 


\section{Abstract}

Polyamine-based carbon dioxide sorbents suffer from a seesaw relationship between amine content and amine efficiency. High polyamine loadings equate to increased amine contents, but often at the expense of amine efficiency. Carbon dioxide mass transport in compact polymers is severely limited, especially at ambient temperature. High polymer contents curtail diffusion pathways, hindering $\mathrm{CO}_{2}$ from reaching and reacting with the numerous amine functions. Here, we overcome this issue using poly(allylamine) (PAA) grafted with short fluoroalkyl chains and then cross-linked with $\mathrm{C}_{60}$. As experimentally evidenced by positron annihilation lifetime spectroscopy, the incorporation of fluoroalkyl chains generates free volume elements that act as additional diffusion pathways within the material. The inclusion of void volume in fluoroalkyl-functionalized PAA sorbents results in radically increased $\mathrm{CO}_{2}$ uptakes and amine efficiencies in diluted gas streams at room temperature, including simulated air. We speculate that the hydrophobic fluorinated functions interfere with the strong amine hydrogen bonding network disrupting and consequently altering the packing and conformation of the polymer chains. The evidence presented here is a blueprint for the development of more efficient amine-based $\mathrm{CO}_{2}$ sorbents.

\section{Introduction}

Global warming and climate change are directly linked to $\mathrm{CO}_{2}$ emissions from fossil fuels combustion. Since 1958, the National Oceanic and Atmospheric Administration has been recording the continuous rise in atmospheric $\mathrm{CO}_{2}$ concentration reaching today $417 \mathrm{ppm} .{ }^{[1]}$ With a mean average growth of about $2.6 \mathrm{ppm}$ per year in the last five years, we are set to witness a record concentration of $500 \mathrm{ppm}$ by 2050 . In the face of such a looming perspective, many countries keep relying on fossil fuels as a primary energy source, while we transition to a net-zerocarbon society. ${ }^{[2]}$ Consequently, remedies are sought to prevent the further release of $\mathrm{CO}_{2}$ and 
enable its removal from the atmosphere. The deployment of carbon capture and storage (CCS) technologies at scale is seen by many as the solution to implement the transition to net-zero emissions. Typically, aqueous amine scrubbing, originally developed in the 1930 s to remove $\mathrm{CO}_{2}$ from natural gas, is acknowledged as the benchmark technology for the removal of $\mathrm{CO}_{2}$ from power plant flue gases, ${ }^{[3]}$ yet it suffers from limited capture capacity, high energy demand, and continuous replenishing of corrosive amines. ${ }^{[4]}$ Nowadays, however, it is clear that decarbonizing power plants, industrial activities, transport, and heating are not sufficient measures to avoid the environmental impact of climate change. Responding to the mounting urgency of reducing atmospheric $\mathrm{CO}_{2}$ concentrations, researchers are increasingly looking towards the development of materials suitable for the capture of $\mathrm{CO}_{2}$ from the air, the concept of direct air capture (DAC). ${ }^{[5]}$ This presents new challenges to carbon capture technologies, not least in the highly diluted nature of the $\mathrm{CO}_{2}$ adsorbate at only around $400 \mathrm{ppm}$, compared to more concentrated $\mathrm{CO}_{2}$ sources such as flue gas $\left(12-15 \% \mathrm{CO}_{2}\right) \cdot{ }^{[6]}$ In the last decade, there has been a growing and sustained effort to develop carbon capture technologies for large-scale application, including $\mathrm{CO}_{2}$ capture with solid sorbents as an alternative to amine scrubbing. ${ }^{[7]}$ Development and optimization of the chemistry and physics of sorbent materials are key steps for the technical feasibility of efficient $\mathrm{CO}_{2}$ capture from flue gas or air. A recent tutorial review suggests six pillars for the optimum design of the sorbent materials, namely capacity, selectivity, thermal and chemical stability, recyclability, low cost, and fast kinetics. ${ }^{[6]}$ Among these factors, the majority of the studies have been directed towards the development of materials with higher capacity, increased selectivity and stability to impurities.

Polyamine-based sorbents have attracted increased attention as promising candidates for DAC due to their high performance and stability. ${ }^{[8]}$ Additionally, their adsorption performance is often 
enhanced by the presence of water ${ }^{[9]}$ a useful feature for adsorbents that would invariably be exposed to some levels of humidity. ${ }^{[10]}$ Besides the amine type, the type of support is a key factor governing the $\mathrm{CO}_{2}$ adsorption performance of immobilized amines. Much research is thus focused on supports and how their properties affect the $\mathrm{CO}_{2}$ uptake capacity. The loading of as much amine as possible on the supports has initially been the objective of solid sorbent development, as two amines are needed to bind one $\mathrm{CO}_{2}$ molecule for the formation of ammonium carbamate pairs, among other related species, in dry gaseous streams. ${ }^{[11]}$ However, thermodynamic and kinetic factors act competitively in the sorption process, ${ }^{[12]}$ and it has been evident that high amine loadings often counteract gas diffusion in the bulk, reducing the $\mathrm{CO}_{2}$ adsorption working capacity. Nonetheless, at higher adsorption temperatures, diffusion may be enhanced to achieve higher $\mathrm{CO}_{2}$ uptakes. ${ }^{[13]}$ Although this may aid post-combustion $\mathrm{CO}_{2}$ adsorption, DAC conditions generally involve ambient temperatures, which for amine-based chemisorbents requires facilitated access to the amine groups. Thus, current studies aim to strike a successful trade-off between amine loading and accessibility to maximize amine efficiency, i.e., the moles of $\mathrm{CO}_{2}$ adsorbed per mole of amine functions.

The main strategies to enhance $\mathrm{CO}_{2}$ diffusion and amine efficiency in solid amine sorbents are (i) the structural modification of the support, (ii) the alteration of the interaction between aminopolymer and support, and (iii) the modification of the polymer itself. Various studies emphasize the structural features of the support and how they affect $\mathrm{CO}_{2}$ uptake. ${ }^{[14]}$ It has been found that high surface area, although able to facilitate maximum amine loading, does not decisively affect capture capacity. ${ }^{[14 \mathrm{~d}]}$ The combination of pore diameter, pore length, and residual pore volume have been identified as the pivotal factors affecting polyamine loading, amine accessibility, and so the $\mathrm{CO}_{2}$ uptake. ${ }^{[14 a-c, 14 f]}$ For example, the three-dimensional interconnected 
porous structure of hierarchical meso/macroporous silica has been shown to prevent pore blockages when impregnated with the commonly studied poly(ethyleneimine) (PEI). ${ }^{[15]}$ With a PEI loading of $2.62 \mathrm{~g} \mathrm{PEI} / \mathrm{g}$ sorbent $(60.8 \mathrm{mmol} \mathrm{N} / \mathrm{g})$ the adsorbent displayed the highest $\mathrm{CO}_{2}$ capacity for a supported polyamine adsorbent under simulated air conditions. At $30{ }^{\circ} \mathrm{C}$, under 400 ppm $\mathrm{CO}_{2}$, the capacity was $2.34 \mathrm{mmol} \mathrm{CO}_{2} \mathrm{~g}^{-1}$ in dry conditions, increasing to $3.36 \mathrm{mmol} \mathrm{CO}_{2} \mathrm{~g}^{-}$ ${ }^{1}$ under a relative humidity of $19 \% .{ }^{[15]}$

Although critical, the structural properties of the support are not the only aspect that impacts on efficient amine loading. It has been reported that surface chemistry has a major effect on adsorption behavior, and tuning the chemical properties of the support can affect adsorption capacity. ${ }^{[16]}$ As previously demonstrated, some of the basic sites of aminosilane-functionalized alumina can directly participate in the adsorption process forming $\mathrm{CO}_{2}$-amine species stabilized via the active participation of the support in the sorption process, especially at low amine loadings. ${ }^{[17]}$ Incorporation of zirconium $(\mathrm{Zr})$ atoms in a silicate framework enhanced the capture capacity and the regenerability of a PEI-based sorbent due to the stabilizing effect of $\mathrm{Zr}$ on PEI, limiting degradation and aggregation. ${ }^{[16 a]}$ Similarly, Rownaghi et al. reported improved uptakes using binary $\mathrm{Zr} / \mathrm{Si}$ or $\mathrm{Ti} / \mathrm{Si}$ and ternary $\mathrm{Zr} / \mathrm{Ti} / \mathrm{Si}$ supported amine sorbents compared to plain silica amine sorbents, and ascribed the superior uptakes to either the active participation of the metal oxides or to their amine stabilising effect. ${ }^{[16 c]}$ On the other hand, a study by Nowak revealed that alteration of the morphological and textural properties of supports has a more pronounced effect than surface chemical modification. ${ }^{[16 d]}$ Hydrophobic features were incorporated onto silica to establish a repulsive interaction with PEI and expose more amine functionality. Indeed, the synthesized sorbent exhibited both higher uptake and sorption rate. ${ }^{[18]}$ The critical point is the interaction of the host support with active amines such that the amines become more easily accessible. Similarly, 
Sayari et al. observed increased amine efficiency in a PEI-based sorbent after doping the silica support with a surface layer of long hydrophobic alkyl chains. The improved efficiency was related to a better dispersion of PEI in the presence of the alkyl chains. ${ }^{[19]}$ In a previous study, we provided evidence that the addition of hydrophobic fullerene to poly(propylenimmine) (PPI) diminished the enthalpic barrier of $\mathrm{CO}_{2}$ capture whilst increasing the entropy of adsorption. We suggested that the repulsive interplay between hydrophobic $\mathrm{C}_{60}$ and hydrophilic amines better exposed the latter to $\mathrm{CO}_{2} \cdot{ }^{[20]}$ Indeed, a separate computational study by Sharma et al. revealed the significance of entropic contributions in $\mathrm{CO}_{2}$ capture in a PEI melt. Entropically favorable free volume was identified as the dominant factor in the sorption process, as higher $\mathrm{CO}_{2}$ solubility values were noticed near the interfaces despite the lower density in sorption sites. ${ }^{[21]}$

Distinct from the aforementioned studies, several groups directly modified the active amine component. ${ }^{[22]}$ Surfactant/diffusion additives were added to the polymer phase aiming to better disperse it onto the support and improve amine efficiency. The observed enhancement was assigned to kinetic factors and was further corroborated by a decrease in the optimum sorption temperature after surfactants addition. Morphology and conformational changes of the polymer after surfactant addition promoted the interaction between amines and $\mathrm{CO}_{2}$. Additives can also increase thermal stability of the sorbent, for example propylene oxide (PO) was added to pentaethylenehexamine (PEHA) and tetraethylenepentamine (TEPA) before impregnation onto silica support significantly improving the oxidative stability of the sorbent. ${ }^{[23]}$ The direct air capture performance of these sorbents was tested at $25^{\circ} \mathrm{C}$, under $400 \mathrm{ppm} \mathrm{CO}_{2}$, and the uptakes were 1.25 and $1.34 \mathrm{mmol} \mathrm{CO}_{2} \mathrm{~g}^{-1}$ for the PEHA and TEPA based adsorbents, respectively. Driven by the above findings on the pivotal role of polymer conformation in the $\mathrm{CO}_{2}$ capture process, and the beneficial effect of hydrophobic features on amine accessibility, we present here the successful 
implementation of a strategy to improve the $\mathrm{CO}_{2}$ capture performance at ambient temperature of highly loaded poly(allylamine) (PAA) fullerene cross-linked sorbents. We demonstrate the creation of free void volume upon inclusion of hydrophobic fluoroalkyl short chains on the aminopolymer, resulting in a dramatic enhancement of both $\mathrm{CO}_{2}$ capture capacity (2.8-fold increase) and amine efficiency (4.1-fold increase). Also, the inclusion of voids allowed achievement of a $\mathrm{CO}_{2}$ uptake of $1.30 \mathrm{mmol} \mathrm{g}^{-1}$ in $400 \mathrm{ppm} \mathrm{CO}_{2}$ at $30{ }^{\circ} \mathrm{C}$, corresponding to a 3fold increase compared to the unmodified sorbent.

\section{Results and discussion}

A solution of PAA was obtained after treating poly(allylamine) hydrochloride in a methanolic solution of caustic alkali $(\mathrm{KOH})$. The exact concentration of PAA present in the resulting solution was determined after solvent removal, as described in the experimental section. Fluoroalkyl groups were grafted to the PAA chains through a nucleophilic addition reaction with glycidyl 2,2,3,3,4,4,5,5-octafluoropentyl ether ( $\mathrm{GOF}$, chemical formula $\mathrm{C}_{8} \mathrm{H}_{8} \mathrm{~F}_{8} \mathrm{O}_{2}$ ) at ambient temperature. Unmodified and GOF-functionalized PAA were subsequently cross-linked with $\mathrm{C}_{60}$, resulting in the formation of PAA- $\mathrm{C}_{60}$ and F-PAA- $\mathrm{C}_{60}$, respectively (see reaction schematic in Figure 1). Scanning electron microscopy (SEM) images of the two materials are provided in Figure S1 of the Supporting Information (SI). F-PAA- $\mathrm{C}_{60}$ with two different GOF loadings were prepared, F1PAA- $\mathrm{C}_{60}$ and F2-PAA- $\mathrm{C}_{60}$, with a higher level of fluoroalkyl functionalization in the latter (Table 1). Energy dispersive X-ray (EDX) spectroscopy was used to confirm the presence of fluorine in F-PAA- $\mathrm{C}_{60}$, demonstrating the incorporation of fluoroalkyl groups in the material, see Figure S2 (see SI). The ring-opening of the epoxide functional group was also confirmed using Fourier Transform Infrared (FTIR) spectroscopy. The FTIR spectrum of F1-PAA-C 60 is shown in Figure

2. The peak at $1165 \mathrm{~cm}^{-1}$ is attributed to the C-O stretching of alcohols. ${ }^{[24]}$ As expected, no such 
peak is observed in the spectrum of PAA- $\mathrm{C}_{60}$. Detailed assignment of the peaks is provided in Figure S3 (see SI).

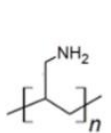

PAA

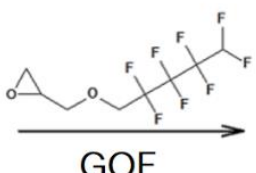

GOF

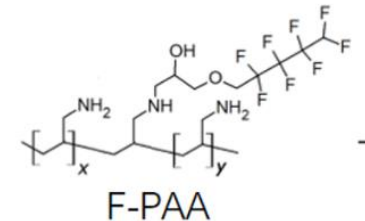

F-PAA

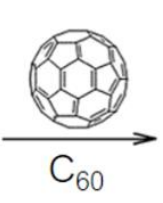

$\mathrm{C}_{60}$

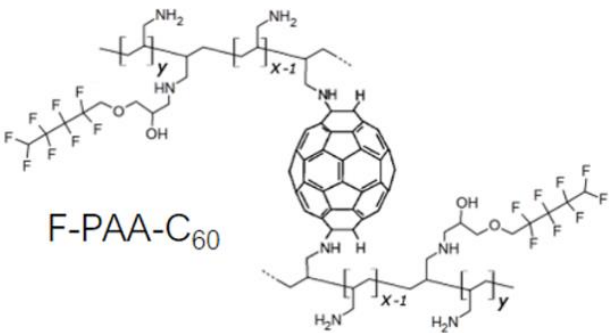

Figure 1. Synthetic route for the grafting of PAA with fluorinated additive GOF to give partially fluorinated F-PAA, and its reaction with fullerene $\mathrm{C}_{60}$ to form F-PAA-C 60 .

The amounts of PAA, $\mathrm{C}_{60}$, and GOF in the materials were determined from the elemental analyses of the vacuum dried samples, assuming all oxygen was solely due to the epoxy rings of the fluoroalkyl groups (Tables $1 \&$ S1, see SI). Detailed calculations are provided in the SI. Clearly, PAA- $\mathrm{C}_{60}$ is a highly loaded polyamine-based material with $80.6 \mathrm{wt} \%$ of its weight due to PAA, and only the remaining $19.4 \mathrm{wt} . \%$ to the cross-linker $\mathrm{C}_{60}$. This compares to polymer loadings of about 70 wt.\% in both poly(ethyleneimine) (PEI)- $\mathrm{C}_{60}$ and poly(propyleneimine) (PPI)- $\mathrm{C}_{60}$ in our previous work. ${ }^{[20,25]}$ As displayed in Table 1, the PAA loading drops to about 60 wt.\% with the inclusion of fluoroalkyl groups in F-PAA-C 60 , and the cross-linker also drops to about 15 wt.\%. The molar ratios of allylamine (AA) monomeric units, fullerene, and GOF were also calculated (Table S1). The AA: $\mathrm{C}_{60}$ molar ratio is about 50:1 (1:0.02) for all materials. It follows that in both PAA- $\mathrm{C}_{60}$ and F-PAA-C 60 there are about 150 polymer carbons per fullerene (since each AA contains 3 carbons). This compares to 120 and 100 polymer carbons per fullerene in PEI-C 60 and PPI-C 60 , respectively. ${ }^{[20,25]}$ It appears that the higher polymer loading of PAA-C 60 and F-PAA-C 60 also corresponds to the largest amount of added carbon per fullerene unit. Thus, it cannot be 


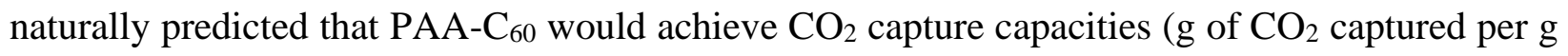
of material) higher than PEI-C 60 and PPI-C 60 , given the more significant amount of carbon present in the sorbent. Even more so in the case of F-PAA- $\mathrm{C}_{60}$, where the fluoroalkyl chains add almost $30 \mathrm{wt} . \%$ extra weight to the sorbent material, corresponding to about one GOF grafted for every 10-12 amines (Table 1). Astonishingly, as demonstrated later in the paper, F-PAA-C 60 can absorb almost as much $\mathrm{CO}_{2}$ as PAA- $\mathrm{C}_{60}$ at its optimum sorption temperature, despite the lower amine content per unit of weight, indicating the beneficial impact of the fluoroalkyl groups to enhance amine efficiency.

Table 1. Chemical composition of the vacuum dried samples according to elemental analysis

\begin{tabular}{|l|l|l|l|l|}
\hline Sample & PAA [wt.\%] & C60 [wt.\%] & GOF [wt.\%] & Molar ratios \\
\hline PAA-C 60 & 80.5 & 19.5 & - & $(\mathrm{AA})_{1}\left(\mathrm{C}_{60}\right)_{0.019}$ \\
\hline F1-PAA-C 60 & 61.3 & 15.2 & 23.4 & $(\mathrm{AA})_{1}\left(\mathrm{C}_{60}\right)_{0.020}(\mathrm{GOF})_{0.075}$ \\
\hline F2-PAA-C 60 & 57.0 & 13.9 & 29.1 & $(\mathrm{AA})_{1}\left(\mathrm{C}_{60}\right)_{0.020}(\mathrm{GOF})_{0.101}$ \\
\hline
\end{tabular}




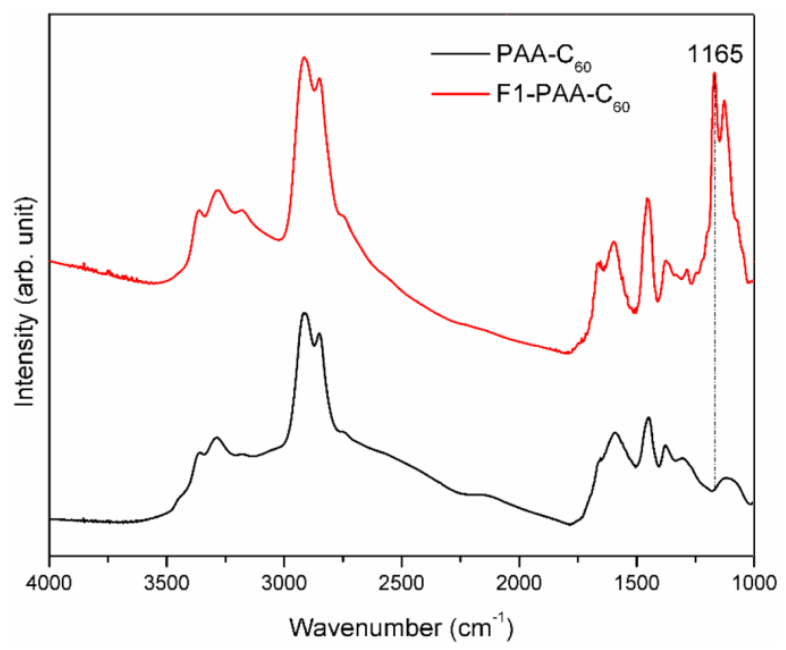

Figure 2. FTIR spectra of PAA- $\mathrm{C}_{60}$ and F1-PAA- $\mathrm{C}_{60}$. Prior to analysis the materials were vacuum-dried at $90{ }^{\circ} \mathrm{C}$. Full peak assignments are given in Figure S3 (see SI).

\section{Carbon dioxide capture}

A major difference between PAA- $\mathrm{C}_{60}$ and its fluoroalkyl-modified versions is the effect of temperature on $\mathrm{CO}_{2}$ uptake. Figure 3 shows the $\mathrm{CO}_{2}$ gravimetric equilibrium uptakes of PAA-C60, F1-PAA- $\mathrm{C}_{60}$, and $\mathrm{F} 2-\mathrm{PAA}-\mathrm{C}_{60}$ in pure $\mathrm{CO}_{2}$ (the gravimetric curves corresponding to each data point are provided in Figure S4, see SI). Clearly, PAA- $\mathrm{C}_{60}$ is a poorer sorbent than F-PAA-C60 at a lower temperature. The $\mathrm{CO}_{2}$ uptake of PAA- $\mathrm{C}_{60}$ decreases with decreasing temperature, whereas the uptake of both F1-PAA- $\mathrm{C}_{60}$ and F2-PAA- $\mathrm{C}_{60}$ improves at a lower temperature (similar trends were observed in $10 \% \mathrm{CO}_{2}$, as shown in Figure S5, see SI). This is a fundamental change in the behavior of the material, highlighting the striking effect of the fluoroalkyl groups on the availability of the polymer amino groups towards $\mathrm{CO}_{2}$ capture. In Figure $3 \mathrm{a}$, the uptake of PAA$\mathrm{C}_{60}$ drops from 0.191 to $0.065 \mathrm{~g} \mathrm{~g}^{-1}$ at 90 and $30^{\circ} \mathrm{C}$, respectively, evidently losing access to $2 / 3$ of its amine functionalities at low temperature. Instead, the capacity of F1-PAA-C 60 increases from 0.120 to $0.143 \mathrm{~g} \mathrm{~g}^{-1}$, almost independent of the change in temperature. This is further enhanced when more fluoroalkyl groups are present in the materials since the capture capacity of F2-PAA- 
$\mathrm{C}_{60}$ improves from 0.143 to $0.178 \mathrm{~g} \mathrm{~g}^{-1}$ at 90 and $30^{\circ} \mathrm{C}$, respectively. The maximum $\mathrm{CO}_{2}$ sorption capacity of PAA- $\mathrm{C}_{60}$ is achieved at $90{ }^{\circ} \mathrm{C}$, the highest useful temperature, since material degradation and performance loss are observed above $90{ }^{\circ} \mathrm{C}$. Increased temperature in the high polyamine loaded PAA-C 60 (80.5 wt.\% PAA) enhances the motion and dynamics of polymer chains, alleviating the diffusion hindrance and allowing the penetration of gaseous $\mathrm{CO}_{2}$ in the bulk of the material..$^{[22 c]}$ On the contrary, an uptake of just $0.065 \mathrm{~g} \mathrm{~g}^{-1}$ at $30{ }^{\circ} \mathrm{C}$ clearly indicates the kinetic inhibition of $\mathrm{CO}_{2}$ diffusion at this temperature. The addition of GOF drastically changes this behavior, with F1-PAA- $\mathrm{C}_{60}$ taking up to 2.2 times more $\mathrm{CO}_{2}$ than PAA-C 60 at $30{ }^{\circ} \mathrm{C}$. This is striking considering the significantly lower polymer content of F1-PAA-C 60 (61.3 wt.\% PAA) compared to PAA-C 60 . A better way to picture the dramatic difference of polymer performance in

a)

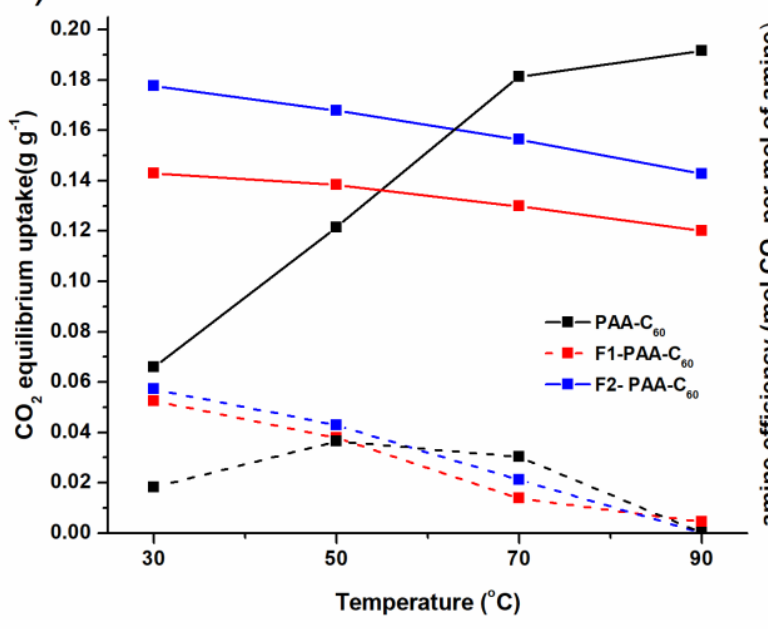

b)

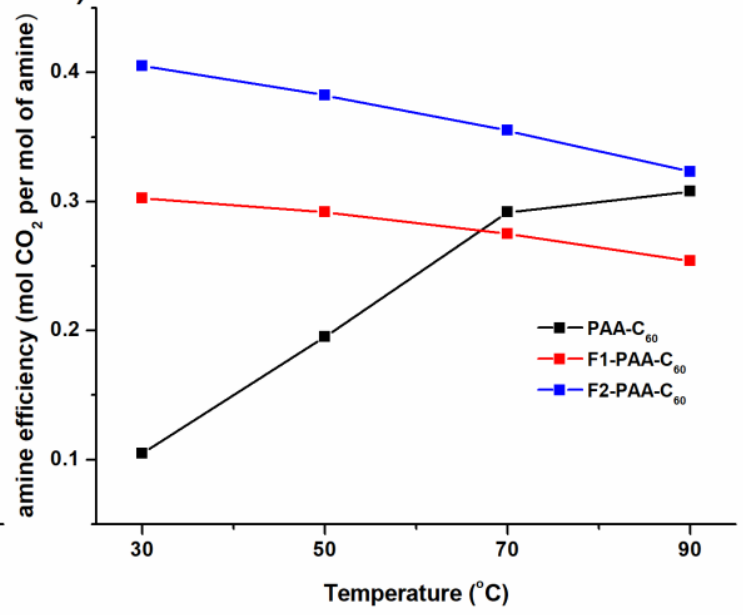

Figure 3. a) $\mathrm{CO}_{2}$ uptake vs temperature for PAA- $\mathrm{C}_{60}$ (black), F1-PAA- $\mathrm{C}_{60}$ (red) and F2PAA- $\mathrm{C}_{60}$ (blue) in $100 \% \mathrm{CO}_{2}$ (solid lines) or $400 \mathrm{ppm} \mathrm{CO}_{2}$ in $\mathrm{N}_{2}$ (dashed lines); b) amine efficiency in $100 \% \mathrm{CO}_{2}$ as a function of temperature, PAA- $\mathrm{C}_{60}$ (black), F1-PAA- $\mathrm{C}_{60}$ (red) and F2-PAA-C 60 (blue). 
the two materials is to normalise the $\mathrm{CO}_{2}$ capture capacity per weight of PAA, the sorptive component. It follows that the polymer in PAA- $\mathrm{C}_{60}$ captures $0.081 \mathrm{~g} \mathrm{CO}_{2}$ per gram of PAA, while in F1-PAA-C 60 it captures $0.233 \mathrm{~g} \mathrm{CO}_{2}$ per gram of PAA at $30{ }^{\circ} \mathrm{C}$. Evidently, the presence of fluoroalkyl groups is beneficial for $\mathrm{CO}_{2}$ capture at a lower temperature. Even more pronounced is the effect observed for F2-PAA-C 60 (57.0 wt.\% PAA), with a $\mathrm{CO}_{2}$ uptake of $0.178 \mathrm{~g} \mathrm{~g}^{-1}$ at $30{ }^{\circ} \mathrm{C}$, an increase of 2.74 times the capacity compared to PAA- $\mathrm{C}_{60}$ despite having almost $1 / 3$ less polymer in the material. This corresponds to $0.312 \mathrm{~g} \mathrm{CO}_{2}$ captured per gram of PAA present in F2-PAA- $\mathrm{C}_{60}$. This high performance is consistent across all the investigated temperature range. The slight decrease of $\mathrm{CO}_{2}$ capture capacity at higher temperature can be associated with weakly bound $\mathrm{CO}_{2}$ in both F1-PAA- $\mathrm{C}_{60}$ and F2-PAA- $\mathrm{C}_{60}$ that can only be adsorbed at a lower temperature. It is also of note, the cyclability displayed by F-PAA- $\mathrm{C}_{60}$ materials. The stability was investigated for 23 consecutive adsorption-desorption cycles (adsorption: $100 \% \mathrm{CO}_{2}$, at $25{ }^{\circ} \mathrm{C}$; desorption: $100 \% \mathrm{~N}_{2}$ at $90^{\circ} \mathrm{C}$ ). The $\mathrm{CO}_{2}$ adsorption-desorption profiles and the relevant $\mathrm{CO}_{2}$ working capacities are shown in Figure S6. After 23 cycles, the working capacity of the GOF-functionalized material dropped from $0.088 \mathrm{~g} \mathrm{~g}^{-1}$ to a substantially steady value of $0.074 \mathrm{~g} \mathrm{~g}^{-1}$ after few cycles.

A comparison of amine efficiency ( $\mathrm{mol}$ of $\mathrm{CO}_{2}$ uptake per mol of amine) between PAA-C 60 and F-PAA- $\mathrm{C}_{60}$ confirms the $\mathrm{CO}_{2}$ capture enhancing effect of the fluoroalkyl additive. In Figure $3 \mathrm{~b}$, the amine efficiency of PAA- $\mathrm{C}_{60}$ is highest at a higher temperature, $0.31 \mathrm{~mol} \mathrm{~mol}^{-1}$ at $90{ }^{\circ} \mathrm{C}(1$ $\mathrm{CO}_{2}$ every 3.3 amines), and lowest at a lower temperature, $0.10 \mathrm{~mol} \mathrm{~mol}^{-1}$ at $30{ }^{\circ} \mathrm{C}\left(1 \mathrm{CO}_{2}\right.$ every 10 amines), corresponding to a dramatic loss of bulk amine accessibility. This inaccessibility is entirely overcome in the presence of GOF. The amine efficiency of F1-PAA- $\mathrm{C}_{60}$ and F2-PAA-C 60 are 3 and 4 times higher than that of PAA- $\mathrm{C}_{60}$ at $30^{\circ} \mathrm{C}$, respectively. The outstanding performance

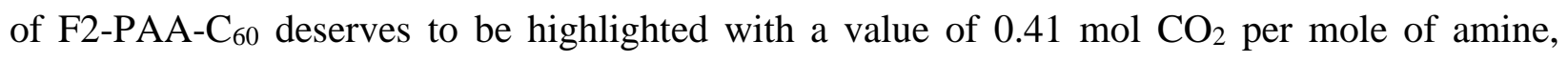


approaching the theoretical maximum ratio of one $\mathrm{CO}_{2}$ molecule captured every two amine groups in dry conditions (ammonium carbamate pathway). ${ }^{[26]}$ These performances have been recorded in pure $\mathrm{CO}_{2}$, however the enhanced amine availability in F-PAA- $\mathrm{C}_{60}$ is expected to boost the $\mathrm{CO}_{2}$ uptake in diluted gas streams too.

Indeed, simulated direct air capture (DAC) from a stream of $400 \mathrm{ppm} \mathrm{CO}_{2}$ in nitrogen further highlights the difference in performance between PAA- $\mathrm{C}_{60}$ and F-PAA- $\mathrm{C}_{60}$. In Figure $3 \mathrm{a}$, all materials display a low DAC uptake at $90{ }^{\circ} \mathrm{C}$ (dashed lines); nonetheless, the performance significantly improves at lower temperature (the gravimetric curves corresponding to each data point are provided in Figure S4, see SI). The DAC capacity of PAA-C 60 goes through a maximum with the highest uptake of $0.036 \mathrm{~g} \mathrm{~g}^{-1}$ measured at $50{ }^{\circ} \mathrm{C}$; the uptake drops to $0.019 \mathrm{~g} \mathrm{~g}^{-1}$ at $30^{\circ} \mathrm{C}$. Instead, the GOF-functionalized materials show the best performance at $30{ }^{\circ} \mathrm{C}$. At this temperature, F1-PAA- $\mathrm{C}_{60}$ and F2-PAA-C 60 capture 0.053 and $0.057 \mathrm{~g} \mathrm{~g}^{-1}$, respectively, demonstrating high $\mathrm{CO}_{2}$-philicity essential for DAC applications. The fluoroalkyl groups in FPAA-C 60 triple the DAC capacity of PAA- $\mathrm{C}_{60}$ at low temperature, in line with the fourfold increase of $\mathrm{CO}_{2}$ uptake observed in a pure $\mathrm{CO}_{2}$ stream. With a DAC capacity of $1.30 \mathrm{mmol} \mathrm{g}^{-1}(2.28 \mathrm{mmol}$ $\mathrm{CO}_{2}$ per gram of PAA) at $30{ }^{\circ} \mathrm{C}, \mathrm{F}-\mathrm{PAA}-\mathrm{C}_{60}$ compares well with other materials reported in the literature such as PEI loaded SBA-15 $\left(1.10 \mathrm{mmol} \mathrm{g}^{-1}\right),{ }^{[27]}$ PEHA or TEPA co-impregnated with PO on silica support (1.25 and $1.34 \mathrm{mmol} \mathrm{g}^{-1}$, respectively), ${ }^{[23]}$ and amine-based nanofibrillated cellulose $\left(1.39 \mathrm{mmol} \mathrm{g}^{-1}\right) \cdot{ }^{[28]}$ A comprehensive table with key features and performance of polyamine-based DAC sorbent materials is provided in the SI, Table S2. The highest DAC capacity recorded to date is $3.36 \mathrm{mmol} \mathrm{g}^{-1}$ in a humidified stream of $400 \mathrm{ppm} \mathrm{CO}_{2}$, Jones and coworkers achieved this outstanding performance using a bimodal meso/macroporous hierarchical silica impregnated with PEI. ${ }^{[15]}$ 
Single component $\mathrm{CO}_{2}$ adsorption isotherms also demonstrate the ability of PAA-C 60 and F-PAA$\mathrm{C}_{60}$ to capture $\mathrm{CO}_{2}$ at low pressure, as shown in Figure 4. At 0.07 bar, mimicking performance in diluted gas streams, PAA-C 60 and F1-PAA-C 60 adsorb $0.026 \mathrm{~g} \mathrm{~g}^{-1}$ and $0.104 \mathrm{~g} \mathrm{~g}^{-1}$ at $25{ }^{\circ} \mathrm{C}$, respectively (inset of Figure 4a). This is again a 4-fold increase of $\mathrm{CO}_{2}$ capture capacity upon introduction of fluoroalkyl groups in the material, in agreement with the gravimetric measurements. At 1 bar and $25{ }^{\circ} \mathrm{C}$, the $\mathrm{CO}_{2}$ uptakes are 0.050 and $0.150 \mathrm{~g} \mathrm{~g}^{-1}$ for PAA-C 60 and F1-PAA- $\mathrm{C}_{60}$, respectively. Further increasing the pressure results only in a slight improvement of $\mathrm{CO}_{2}$ capture, evidence of the limited effect of pressure on the accessibility of bulk amino groups. In the case of PAA- $\mathrm{C}_{60}$, the bulk amino groups become accessible when the temperature is increased to $90{ }^{\circ} \mathrm{C}$, reaching an uptake of $0.208 \mathrm{~g} \mathrm{~g}^{-1}$ at 5 bar. This is not observed for F1-PAA$\mathrm{C}_{60}$, where the $\mathrm{CO}_{2}$ capture capacity is lower at a higher temperature, i.e. $0.122 \mathrm{~g} \mathrm{~g}^{-1}$ at $90{ }^{\circ} \mathrm{C}$ instead of $0.177 \mathrm{~g} \mathrm{~g}^{-1}$ at $25^{\circ} \mathrm{C}$ and 5 bar. This shows that at $90{ }^{\circ} \mathrm{C}$ the interaction of $\mathrm{CO}_{2}$ is stronger with PAA- $\mathrm{C}_{60}$ than with F1-PAA- $\mathrm{C}_{60}$ since more thermal energy weakens the $\mathrm{CO}_{2}$-amine interaction only in the presence of fluoroalkyl groups. Supporting evidence to this observation is given later, where the isosteric heat of $\mathrm{CO}_{2}$ adsorption is greater for PAA-C $60\left(110 \mathrm{~kJ} \mathrm{~mol}^{-1}\right)$ than F1-PAA-C $60\left(70 \mathrm{~kJ} \mathrm{~mol}^{-1}\right)$ for a $\mathrm{CO}_{2}$ loading of about $0.080 \mathrm{~g} \mathrm{~g}-1$ at $90{ }^{\circ} \mathrm{C}$.

A comparison of the $\mathrm{CO}_{2}$ sorption kinetics of PAA- 60 and F1-PAA-C 60 is provided in Figure 4. The plot in Figure $4 \mathrm{~b}$ shows the amount of $\mathrm{CO}_{2}$ adsorbed by each sorbent upon the addition of a first dose of $\mathrm{CO}_{2}$, starting with the materials in a vacuum at either 25 or $90{ }^{\circ} \mathrm{C}$. The uptakes reach their plateaus once the materials are fully saturated with $\mathrm{CO}_{2}$ (corresponding to a rate of pressure drop of less than $0.01 \mathrm{mbar} / \mathrm{min})$. Likewise, Figure $4 \mathrm{c}$ shows the uptakes upon the addition of a second dose of $\mathrm{CO}_{2}$, starting from the equilibrium conditions of the first dose. Figure $4 \mathrm{~d}$ is a 
(a)

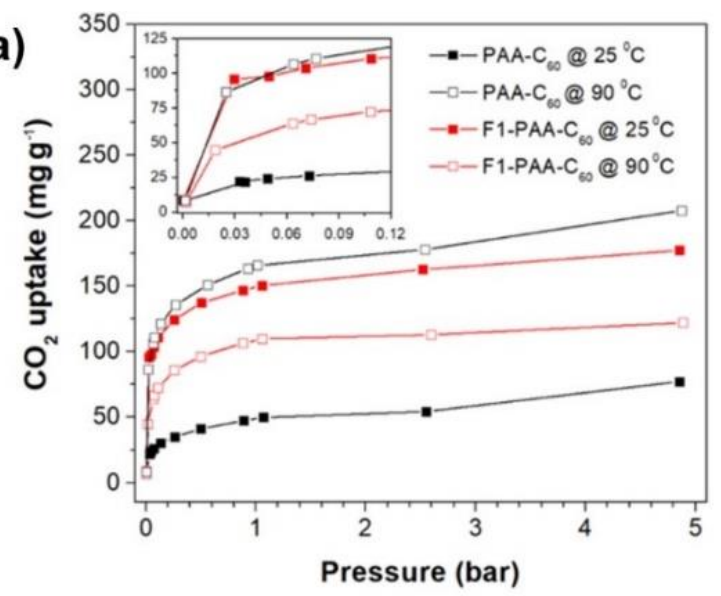

(c)

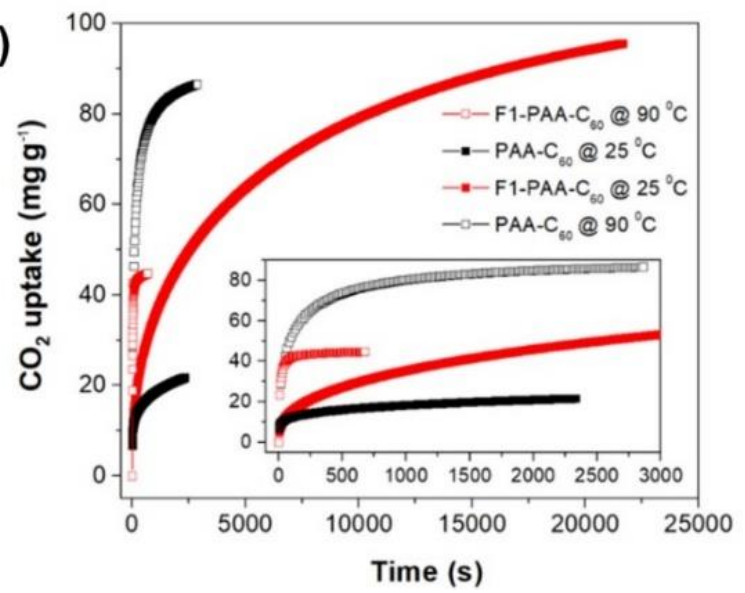

(b)

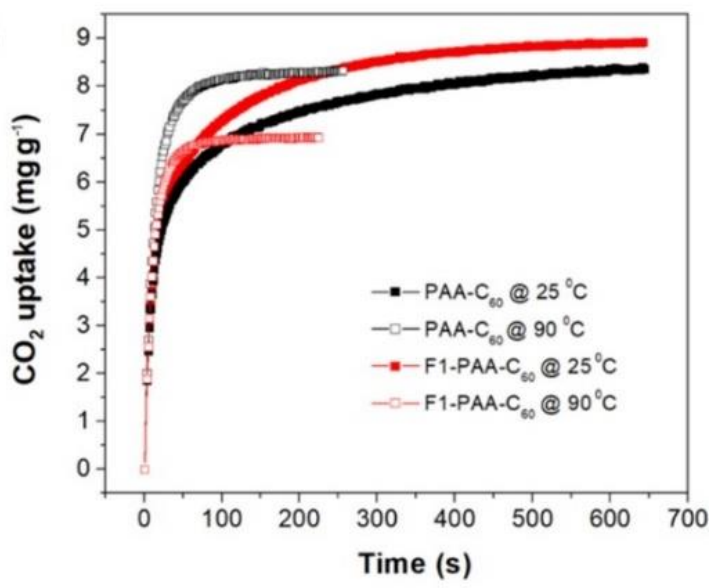

(d)

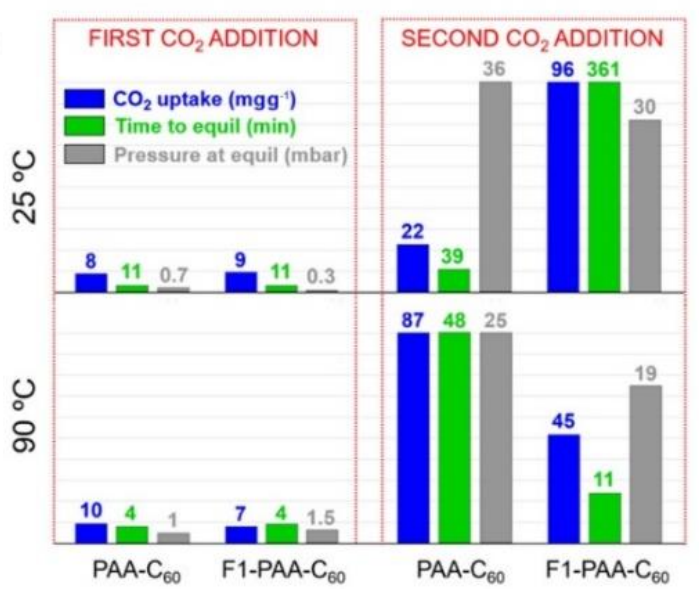

Figure 4. a) $\mathrm{CO}_{2}$ adsorption isotherms of PAA- $\mathrm{C}_{60}$ (black) and $\mathrm{F} 1-\mathrm{PAA}-\mathrm{C}_{60}$ (red) at $25{ }^{\circ} \mathrm{C}$ (filled symbols) and $90{ }^{\circ} \mathrm{C}$ (empty symbols). b) Kinetics of $\mathrm{CO}_{2}$ uptake after exposure of the sorbents to a first dose of $\mathrm{CO}_{2}$ for PAA-C 60 (black) and F1-PAA- $\mathrm{C}_{60}$ (red) at $25{ }^{\circ} \mathrm{C}$ (filled symbols) and $90{ }^{\circ} \mathrm{C}$ (empty symbols). c) The same of b) but for a second dose of $\left.\mathrm{CO}_{2} . \mathrm{d}\right) \mathrm{CO}_{2}$ uptake ( $\mathrm{mg} \mathrm{g}^{-1}$, colored in blue), time to (min, colored in green) and pressure at (mbar, colored in grey) equilibrium for PAA- $\mathrm{C}_{60}$ and F1-PAA- $\mathrm{C}_{60}$ after the first and second dose of $\mathrm{CO}_{2}$ at 25 and $90{ }^{\circ} \mathrm{C}$ (the exact values are shown on the top of the bars; for each parameter, the height of the bars is normalised against the highest value).

summary of the equilibrium uptakes, times required to reach equilibrium, and equilibrium pressures achieved by each material after the first and second dose of $\mathrm{CO}_{2}$ at 25 and $90{ }^{\circ} \mathrm{C}$, 
respectively (made from the data presented in Figures 4a, b, and c). Focusing on the data collected after the first dose, it is evident that there is no major difference between the $\mathrm{CO}_{2}$ sorption performance of PAA- $\mathrm{C}_{60}$ and F1-PAA- $\mathrm{C}_{60}$ at both 25 and $90{ }^{\circ} \mathrm{C}$. Both materials achieved similar uptakes ( 8 and $9 \mathrm{mg} \mathrm{g}^{-1}$, at $25{ }^{\circ} \mathrm{C}$, and 10 and $7 \mathrm{mg} \mathrm{g}^{-1}$, at $90{ }^{\circ} \mathrm{C}$, for each material respectively) within comparable times (11 and 4 min for both materials at 25 and $90{ }^{\circ} \mathrm{C}$, respectively) and final equilibrium pressures $\left(0.7\right.$ and $0.3 \mathrm{mbar}$, at $25^{\circ} \mathrm{C}$, and 1 and $1.5 \mathrm{mbar}$, at $90{ }^{\circ} \mathrm{C}$, for each material respectively). It is only after the second dose that the different $\mathrm{CO}_{2}$ sorption behavior of the two materials becomes evident. At $25^{\circ} \mathrm{C}, \mathrm{F} 1-\mathrm{PAA}-\mathrm{C}_{60}$ adsorbed $96 \mathrm{mg} \mathrm{g}^{-1}$ of $\mathrm{CO}_{2}$ compared to just 22 mg g-1 for PAA- $\mathrm{C}_{60}$, highlighting the better low temperature accessibility of amino groups in the fluoroalkyl-modified sorbent. However, it is also relevant to note that the kinetics of sorption in F1-PAA- $\mathrm{C}_{60}$ is slow since it took 361 min (6 hours) for equilibrium to be reached with a final pressure of 30 mbar $\mathrm{CO}_{2}$. The opposite situation was observed at $90{ }^{\circ} \mathrm{C}$ since it was PAA-C 60 to adsorb $87 \mathrm{mg} \mathrm{g}^{-1}$ of $\mathrm{CO}_{2}$ instead of F1-PAA-C 60 with $45 \mathrm{mg} \mathrm{g}^{-1}$ after the second dose of $\mathrm{CO}_{2}$ (Figure 4c). Clearly, the incorporation of fluoroalkyl additive in the sorbent facilitates the $\mathrm{CO}_{2}$ transport in the sorbent.

\section{Microcalorimetry}

The enhanced $\mathrm{CO}_{2}$ sorption performance of the fluoroalkyl-modified adsorbents at low temperature prompted us to further investigate the amine- $\mathrm{CO}_{2}$ interaction by measuring the heat of adsorption (Qst). In the literature, isosteric heat of adsorption values are often obtained by applying the Clausius-Clapeyron equation to models fitted to multiple adsorption isotherms collected at various temperatures. ${ }^{[9 c, 29]}$ A more accurate method of measurement is to determine the Qst values directly via microcalorimetry, ${ }^{[30]}$ as it was previously shown that the former method can be prone to erroneous results, when comparing the Qst values for aminosilica materials

obtained via both techniques. ${ }^{[31]}$ For this study, we used a Tian-Calvet calorimeter to measure the 
heat released during the interaction of PAA- $\mathrm{C}_{60}$ and $\mathrm{F} 1-\mathrm{PAA}-\mathrm{C}_{60}$ with $\mathrm{CO}_{2}$ at incremental pressures, providing the energetics of $\mathrm{CO}_{2}$ binding for both materials. The $\mathrm{CO}_{2}$ uptakes shown in Figure 5a are in very good agreement with those previously presented in Figure 4a (see inset). It is worth noting that only for PAA- $\mathrm{C}_{60}$, the amount of $\mathrm{CO}_{2}$ captured at $25{ }^{\circ} \mathrm{C}$ (Figure $4 \mathrm{a}$ ) is about half of that adsorbed at $30{ }^{\circ} \mathrm{C}$ (Figure 5a); evidence of the strong temperature dependence of $\mathrm{CO}_{2}$ mass transport in the sorbent without fluoroalkyl modification. Figure $5 \mathrm{~b}$ is a plot of the Qst values measured in relation to the $\mathrm{CO}_{2}$ uptakes. At near-zero $\mathrm{CO}_{2}$ coverage (ca. $3 \mathrm{mg} \mathrm{g}^{-1}$ ), the Qst values lay between 99 and $115 \mathrm{~kJ} \mathrm{~mol}^{-1}$ at both 30 and $90{ }^{\circ} \mathrm{C}$ for both PAA-C 60 and F1-PAA-C 60 , values typically observed for chemisorption, i.e., for chemical reactions between $\mathrm{CO}_{2}$ and the amino groups of the sorbent material. ${ }^{[32]}$ This is close to the value of $93 \mathrm{~kJ} \mathrm{~mol}^{-1}$ at adsorption of 0.03 mmol CO $2 / g\left(1.32 \mathrm{mg} \mathrm{g-1)} \mathrm{for} \mathrm{PEI-impregnated} \mathrm{SBA-15,}{ }^{[30]}\right.$ and $98 \mathrm{~kJ} \mathrm{~mol}^{-1}$ for zero $\mathrm{CO}_{2}$ coverage on 3-amino-propyltriethoxysilane-functionalized MCM-41 silica, ${ }^{[33]}$ both measured at $30{ }^{\circ} \mathrm{C}$ via microcalorimetry. Similarly, high Qst values at low loadings have been reported for polyaldehyde phosphorous dendrimer cross-linked PEI $\left(103 \mathrm{~kJ} \mathrm{~mol}^{-1}\right),{ }^{[34]}$ and triamine surface-modified poreexpanded-MCM-41 (> $\left.90 \mathrm{~kJ} \mathrm{~mol}^{-1}\right) \cdot{ }^{[35]}$ High Qst values were attributed to high amine loading and the proximity of available amine sites to form alkyl ammonium carbamate species upon adsorption of $\mathrm{CO}_{2} \cdot{ }^{[30]}$ At low $\mathrm{CO}_{2}$ coverage, it appears that the Qst values at $30^{\circ} \mathrm{C}$ are roughly $5-15 \mathrm{~kJ} \mathrm{~mol}^{-1}$ lower than those measured at $90^{\circ} \mathrm{C}$, for F1-PAA- $\mathrm{C}_{60}$ and PAA- $\mathrm{C}_{60}$, respectively, showing a slight dependence of the heat of $\mathrm{CO}_{2}$ sorption on temperature, which is most significant for PAA-C 60 . The heat of adsorption of PAA-C 60 is strongly dependent on $\mathrm{CO}_{2}$ sorption temperature (Figure 5). At $30{ }^{\circ} \mathrm{C}$, the Qst values drop sharply with increased $\mathrm{CO}_{2}$ loading. In going from about 3 to 44 mg g-1 CO 2 uptake, the heat of sorption drops drastically from $99 \mathrm{~kJ} \mathrm{~mol}^{-1}$, strongly indicative of chemisorption, to $13 \mathrm{~kJ} \mathrm{~mol}^{-1}$, below the boundary for physisorption interactions. ${ }^{[6]}$ 
(a)

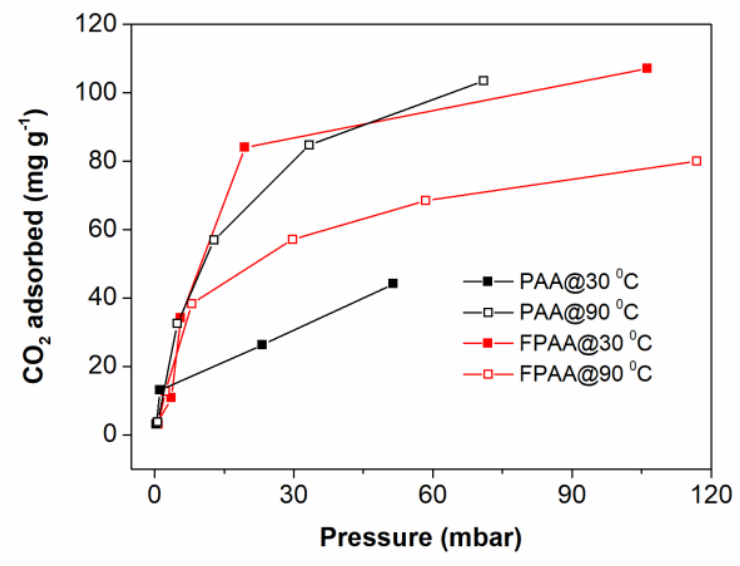

(b)

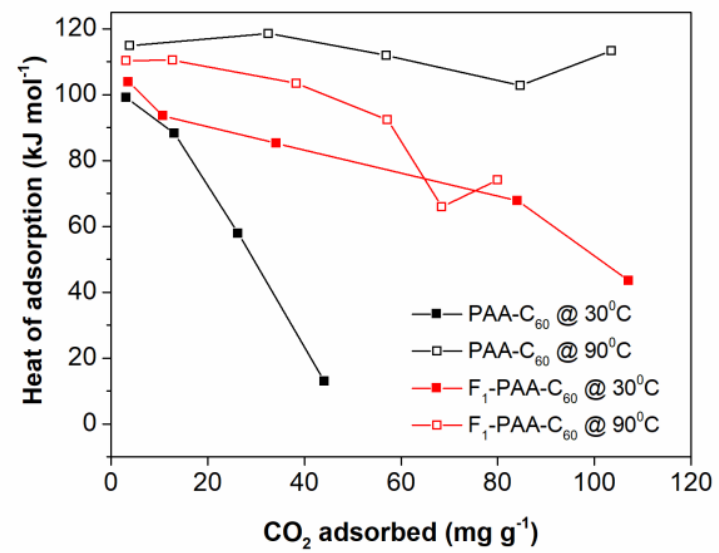

Figure 5. a) $\mathrm{CO}_{2}$ uptake and b) isosteric heat of adsorption of PAA- $\mathrm{C}_{60}$ (black) and F1-PAA$\mathrm{C}_{60}$ (red) measured at $30{ }^{\circ} \mathrm{C}$ (filled symbols) and $90{ }^{\circ} \mathrm{C}$ (empty symbols).

As discussed, PAA- $\mathrm{C}_{60}$ is affected by substantial $\mathrm{CO}_{2}$ diffusion limitations at $30{ }^{\circ} \mathrm{C}$, therefore, at low loadings (up to $10 \mathrm{mg} \mathrm{g}^{-1}$ ), $\mathrm{CO}_{2}$ can chemisorb only on the most accessible amine sites present on the surface of the material. This is in line with the two-site adsorption behavior described by Serna-Guerrero et al., ${ }^{[36]}$ in which once the outermost amines are saturated with chemisorbed $\mathrm{CO}_{2}$ at low initial pressures, additional $\mathrm{CO}_{2}$ can only be captured through weak physical interactions resulting in low heats of adsorption - less than $20 \mathrm{~kJ} \mathrm{~mol}^{-1}$ for $\mathrm{CO}_{2}$ loadings above $40 \mathrm{mg}$ g-1 for PAA- $\mathrm{C}_{60}$. Most of the amines within the bulk of PAA- $\mathrm{C}_{60}$ are not accessible at $30{ }^{\circ} \mathrm{C}$, resulting in low $\mathrm{CO}_{2}$ adsorption, and the presence of strong electrostatic interactions among any surface alkyl ammonium carbamate species is likely to obstruct this access further. ${ }^{[15]}$ This obstruction is overcome at $90{ }^{\circ} \mathrm{C}$, when $\mathrm{CO}_{2}$ diffusion into the bulk of the material, and subsequent $\mathrm{CO}_{2}$ adsorption, is greatly enhanced. This is evidenced in that, at $90{ }^{\circ} \mathrm{C}$, the Qst values are above 100 $\mathrm{kJ} \mathrm{mol}^{-1}$ at all investigated $\mathrm{CO}_{2}$ loadings, up to above $100 \mathrm{mg} \mathrm{g}^{-1}$. This demonstrates that temperature has a major effect on the accessibility of amines in PAA- $\mathrm{C}_{60}$. 
The heat of adsorption of F1-PAA- $\mathrm{C}_{60}$ is substantially less affected by the $\mathrm{CO}_{2}$ sorption temperature (Figure 5b). At both 30 and $90^{\circ} \mathrm{C}$, the Qst of F1-PAA-C 60 decreases with increasing $\mathrm{CO}_{2}$ coverage, with the two trends laying between those of PAA- $\mathrm{C}_{60}$ recorded at the two temperatures. The Qst values diminish about linearly from ca. 110 to $40 \mathrm{~kJ} \mathrm{~mol}^{-1}$ in going from ca. 3 to $105 \mathrm{mg} \mathrm{g}^{-1}$, respectively. It has been observed that the fluorinated additive of F-PAA-C 60 raises $\mathrm{CO}_{2}$ adsorption capacity at $30{ }^{\circ} \mathrm{C}$ (Figure 5a) and influences the adsorbent $\mathrm{CO}_{2}$ uptakes and amine efficiencies (Figure 3b), such that they are more consistent across the investigated range of temperatures in comparison to PAA- $\mathrm{C}_{60}$. In Figure $5 \mathrm{~b}$ it can be seen that, at $30{ }^{\circ} \mathrm{C}$, the inclusion of the fluoroalkyl additive raises the Qst values of F-PAA- $\mathrm{C}_{60}$, bringing about a similar effect on the Qst values at comparable $\mathrm{CO}_{2}$ loadings as does increasing the temperature of adsorption for PAA- $\mathrm{C}_{60}$ to $90{ }^{\circ} \mathrm{C}$. This is due to the greater diffusivity that the F-PAA- 60 allows for $\mathrm{CO}_{2}$, enabling the formation of more ammonium carbamate species and higher adsorption capacity. At $90{ }^{\circ} \mathrm{C}$, the Qst values of F-PAA-C 60 are lower than PAA- $\mathrm{C}_{60}$ at similar $\mathrm{CO}_{2}$ loadings. Higher Qst values are observed for adsorbents of higher amine density. ${ }^{[31 a]}$ The disruptive effect of the fluoroalkyl chains of F-PAA- $\mathrm{C}_{60}$ may result in a higher incidence of isolated amines that are prevented from forming ammonium carbamate species with a neighboring amine. Instead, they form more of the less stable carbamic acid, which has a lower heat of adsorption, ${ }^{[27]}$ and reduced uptakes of $\mathrm{CO}_{2}$ are observed. This is entirely in line with our previous work on poly(propylenimmine) (PPI) cross-linked $\mathrm{C}_{60}$, where increasing hydrophobicity reduced the overall activation energy barrier for adsorption. ${ }^{[20]}$ 


\section{In-situ transmission FTIR spectroscopy}

The chemical species formed upon $\mathrm{CO}_{2}$ adsorption on PAA- $\mathrm{C}_{60}$ and $\mathrm{F} 1-\mathrm{PAA}-\mathrm{C}_{60}$ were investigated using in-situ FTIR in dry $\mathrm{CO}_{2}$. In line with the previous measurements, two temperatures were investigated, namely 30 and $90{ }^{\circ} \mathrm{C}$. Interestingly, no considerable differences were observed in the FTIR spectra recorded at the two temperatures for each material (Figures 6 $\& \mathrm{~S} 7$, see SI). Evidence of $\mathrm{CO}_{2}$ adsorption species should appear with peaks in the region between 1800 and $1300 \mathrm{~cm}^{-1}$. In Figure 6, the peak at $1690 \mathrm{~cm}^{-1}$ is assigned to the $\mathrm{C}=\mathrm{O}$ stretching of carbamic acid; ${ }^{[37]}$ this peak is more intense in $\mathrm{F} 1-\mathrm{PAA}-\mathrm{C}_{60}$, possibly due to the presence of hydroxyl group in the material after epoxide addition and its capability to stabilize carbamic

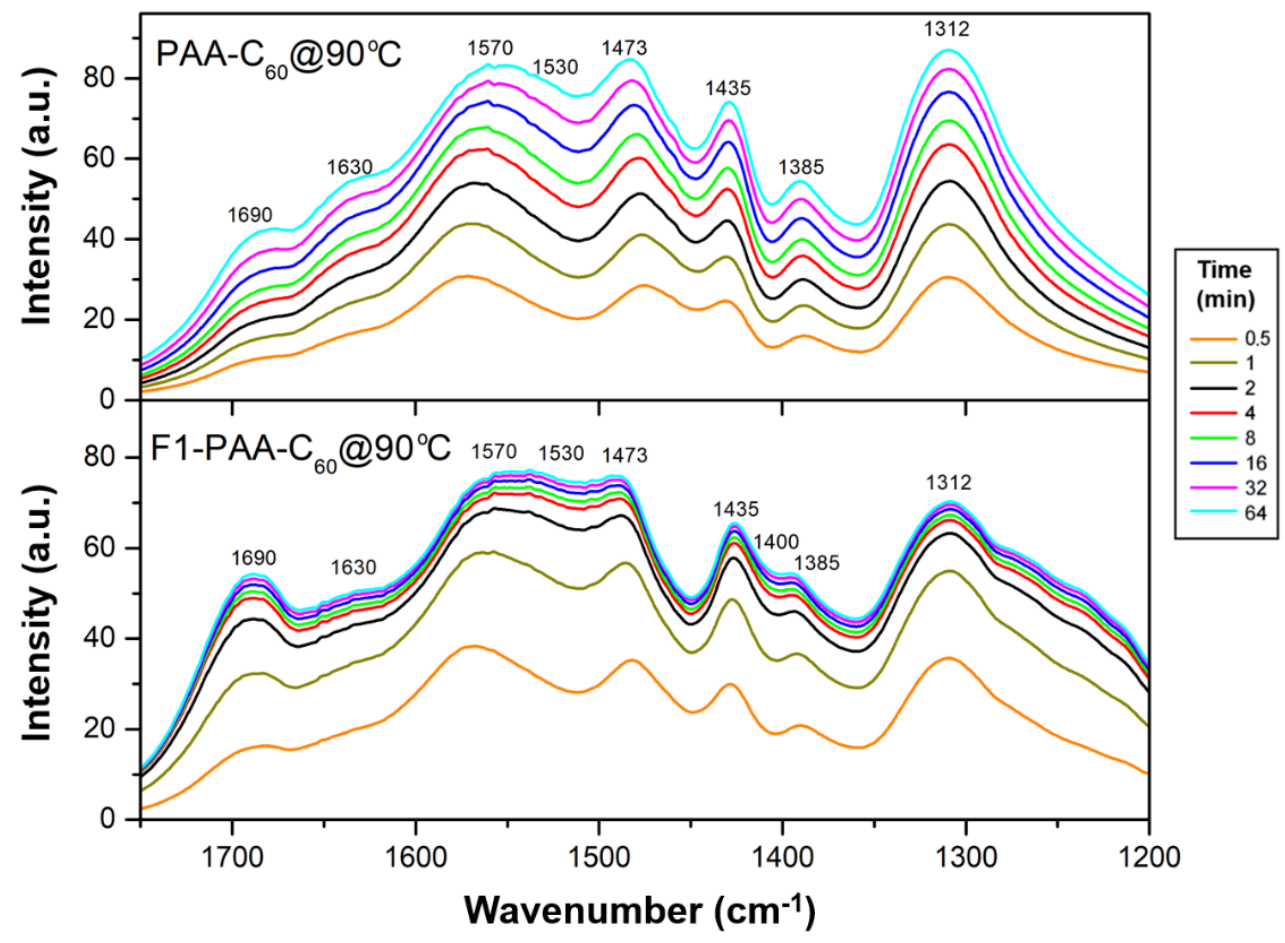

Figure 6. In-situ FTIR spectra for $\mathrm{CO}_{2}$ sorption of PAA- $\mathrm{C}_{60}$ and F1-PAA-C 60 collected overtime in one component pure $\mathrm{CO}_{2}$ at $90{ }^{\circ} \mathrm{C}$ and atmospheric pressure. 
acid. ${ }^{[38]}$ Likewise, the shoulder at $1400 \mathrm{~cm}^{-1}$ is related to the $\mathrm{OH}$ bending vibration of carbamic acid, which is also more prominent in the case F1-PAA- $\mathrm{C}_{60}$ compared PAA-C 60 . The peak at 1630 $\mathrm{cm}^{-1}$ and shoulder at $1530 \mathrm{~cm}^{-1}$ are assigned to $\mathrm{NH}_{3}{ }^{+}$asymmetric deformation, while the band at $1473 \mathrm{~cm}^{-1}$ corresponds to $\mathrm{NH}_{3}{ }^{+}$symmetric deformation. The bands at 1570,1435 and $1385 \mathrm{~cm}^{-1}$ are related to the formation of ammonium carbamate pairs and specifically the carbamate ion groups. The time evolution of the spectra of F1-PAA- $\mathrm{C}_{60}$ is clearly faster than that of PAA- $\mathrm{C}_{60}$ at $90{ }^{\circ} \mathrm{C}$, demonstrating quicker $\mathrm{CO}_{2}$ sorption kinetics in the former. Clearly, both carbamic acid and ammonium carbamate species are formed upon adsorption of $\mathrm{CO}_{2}$ in both PAA-C 60 and F1-PAA$\mathrm{C}_{60}$, but faster in the fluoroalkyl modified material.

\section{Positron annihilation lifetime spectroscopy (PALS)}

The effect of GOF on the evolution of free volume elements in cross-linked PAA sorbents was investigated. To this purpose, PALS was applied, which is an experimental method suitably used for the quantitative measurement of the free volume at the nano and mesoscale in molecular matter and polymers (see SI). ${ }^{[39]}$ The low electron density in void spaces favors the formation of a bond state between an electron and a positron, called positronium (Ps). A direct correlation is found between the size of the free volume and the lifetime of the triplet state, i.e. the ortho-positronium (o-Ps) located in the void. According to the Tao-Eldrup model, the lifetime, $\tau$, of o-Ps in the pickoff processes is a function of the free volume radius, $R$, which is approximated by a sphere: ${ }^{[40]}$

$$
\tau[n s]=0.5\left[1-\frac{R}{R+\Delta}+\frac{1}{2 \pi} \sin \left(2 \pi \frac{R}{R+\Delta}\right)\right]^{-1}
$$

where $\Delta$ is the empirical parameter $(\Delta=0.1656 \mathrm{~nm})$ describing the depth of penetration of the positron wave function and range of overlap with electrons wavefunctions. This relationship is 
used in this study for the determination and analysis of the free-volume present in plain and alkylfluorinated PAA- $\mathrm{C}_{60}$.

Three lifetime components were resolved in all measured positron annihilation spectra to obtain a satisfactory $\chi^{2}$ close to unity (Figure S8, see SI). The first component was close to $0.2 \mathrm{~ns}$ (annihilation of free positrons and/or p-Ps), the second one approached 0.4 ns (due to the annihilation of trapped positrons at molecular defects other than free positron states), but the most interesting one is the longest, the third component, which is associated with the o-Ps formation and annihilation in the free volume. The values, intensities and calculated radii of free volume elements of the third component for both PAA- $\mathrm{C}_{60}$ and F1-PAA- $\mathrm{C}_{60}$ are summarized in Table 2.

Table 2. The values of the longest lifetime components $\tau_{3}$ with their intensities $I_{3}$ and calculated, according to Eq. 1, radius $R$ of the free volume resolved from the positron lifetime spectra measured for the PAA- $\mathrm{C}_{60}$ and F1-PAA- $\mathrm{C}_{60}$ samples. Both samples were annealed at $90{ }^{\circ} \mathrm{C}$ under Ar atmosphere prior to PALS measurements. Uncertainties are shown in parentheses.

\begin{tabular}{llll}
\hline Sample & $\tau_{3}[\mathbf{n s}]$ & $\boldsymbol{I}_{3}[\%]$ & $\boldsymbol{R}[\mathbf{n m}]$ \\
\hline PAA-C $_{60}$ & $1.71(0.04)$ & $5.02(0.30)$ & $0.256(0.004)$ \\
F1-PAA-C 60 & $2.10(0.17)$ & $1.76(1.2)$ & $0.294(0.015)$ \\
\hline
\end{tabular}

We observed a long lifetime component of about $1.71 \mathrm{~ns}$ in $\mathrm{PAA}-\mathrm{C}_{60}$ and $2.10 \mathrm{~ns}$ in F1-PAA-C 60 , confirming the presence of free volume in the molecular structure with approximate radii of 0.256 $\mathrm{nm}$ for PAA- $\mathrm{C}_{60}$ and $0.294 \mathrm{~nm}$ for F1-PAA-C 60 . One should also notice the small intensity values of these components, which are about $5.02 \%$ for PAA- $\mathrm{C}_{60}$ and $1.76 \%$ for F1-PAA-C 60 . These low intensities were attributed to the quenching effect of $\mathrm{C}_{60}$ molecules on Ps formation, further exacerbated by the additional quenching effect of highly electronegative fluorine. The results show 
that the fluoroalkyl groups grafted on PAA chains increase the size of the free volume elements. We thus envisage that the incorporation of hydrophobic GOF disrupts the hydrogen bonding and the chain packing within PAA macromolecules, creating additional interchain spacing which effectively acts as extra $\mathrm{CO}_{2}$ diffusion pathways. This can facilitate the diffusion of $\mathrm{CO}_{2}$ molecules and enhance the gas transport properties of highly loaded amines at ambient temperature. ${ }^{[8]}$ An increase of radius of about $0.04 \mathrm{~nm}$ (ca. 16\%) of the free volume elements, while misleadingly minor, is indeed critical to facilitate $\mathrm{CO}_{2}$ transport and substantially increase the $\mathrm{CO}_{2}$ sorption properties of the fluorinated sorbents in comparison with their bare counterparts. This is in agreement with work by Song et al. where an increase of radius of free volume elements of 0.03 to $0.06 \mathrm{~nm}$ in polyimide membranes, via the inclusion of ZIF-8 nanoparticles, was instrumental to considerably enhance the gas permeation properties of the membranes. ${ }^{[41]}$ Other authors have observed similar direct correlations between improved gas permeabilities and increased o-Ps lifetimes in polyimide membranes. ${ }^{[42]}$

\section{Conclusions}

The functionalization of poly(allylamine) (PAA), an aminopolymer exclusively containing primary amines, with short fluoroalkyl chains, resulted in a drastic change in $\mathrm{CO}_{2}$ capture performance. The fluoroalkyl-modified PAA sorbent boasted an almost tripled $\mathrm{CO}_{2}$ uptake capacity and more than quadruple increases amine efficiency at ambient temperature. The fluoroalkyl chains increased the amount of free void volume present in the sorbent, which in turn facilitated the diffusion of $\mathrm{CO}_{2}$ in the bulk of the polymer. In simulated direct air capture conditions, the fluorinated sorbent achieved a significant $\mathrm{CO}_{2}$ capture capacity of $1.30 \mathrm{mmol} \mathrm{g}^{-1}$, corresponding to $2.28 \mathrm{mmol} \mathrm{CO}_{2}$ per gram of polymer. These results demonstrate that the inclusion of void volume via the addition of incompatible hydrophobic fluoroalkyl chains in hydrophilic 
polyamines is a workable approach to enable drastic improvement of carbon capture performance together with impressive amine efficiencies at a lower temperature.

\section{Experimental Section}

\section{Materials}

Poly(allylamine) hydrochloride (PAH; analytical grade, MW 120,000-180,000 g/mol) was provided by Alfa Aesar. Fullerene $\mathrm{C}_{60}(99.5 \%)$, glycidyl 2,2,3,3,4,4,5,5-octafluoropentyl ether (GOF; 96\%), and triethylamine ( $\geq 99.5 \%$ ) were purchased from Sigma Aldrich. Potassium hydroxide (99.98\%) was obtained from Acros, while methanol (HPLC, 99.8\%) was purchased from Fischer Scientific. The dialysis tube with a molecular weight cut-off (MWCO) of 6,000$8,000 \mathrm{~g} / \mathrm{mol}$ was obtained from Spectrum.

\section{Synthesis}

$\boldsymbol{P A A}-\boldsymbol{C}_{60}$ : PAH ( $\left.0.2 \mathrm{~g}\right)$ was added in small portions to a solution of potassium hydroxide $(0.6 \mathrm{~g})$ in methanol $(6 \mathrm{~mL})$. The solution was stirred for $48 \mathrm{~h}$ at room temperature and subsequently centrifuged to separate the precipitated potassium chloride. The supernatant was dialyzed against methanol to completely remove the excess potassium hydroxide. Chloroform $(24 \mathrm{~mL})$ was added to the methanolic solution of $\mathrm{PAH}$ and mixed afterwards with a $\mathrm{C}_{60}$ solution (24 mg in $44 \mathrm{~mL}$ of toluene) in the presence of triethylamine $(1 \mathrm{~mL})$. A dark grey precipitate was formed and filtered on a $0.45 \mu \mathrm{m}$ PTFE filter (Chemlab MTF100047H). The PAA-C 60 precipitate was dried at $80^{\circ} \mathrm{C}$ in an oven under air overnight and then collected.

$\boldsymbol{F}-\boldsymbol{P A A}-\boldsymbol{C}_{60}$ : PAH $(0.2 \mathrm{~g})$ was added in small portions to a solution of potassium hydroxide $(0.6 \mathrm{~g})$ in methanol $(6 \mathrm{~mL})$. The solution was stirred for $48 \mathrm{~h}$ at room temperature and subsequently centrifuged to separate the precipitated potassium chloride. The supernatant was dialyzed against 
methanol to completely remove the excess potassium hydroxide. Obtained PAA solution (8 mL) was mixed with 31.6 and $38 \mu \mathrm{L}$ of GOF, for F1-PAA- $\mathrm{C}_{60}$ and F2-PAA-C 60 , respectively, for $24 \mathrm{~h}$ at room temperature. Chloroform $(24 \mathrm{~mL})$ was then added to the functionalized PAA solution and afterwards mixed with a $\mathrm{C}_{60}$ solution $(24 \mathrm{mg}$ in $44 \mathrm{~mL}$ of toluene) in the presence of triethylamine $(1 \mathrm{~mL})$. A brown/grey precipitate was formed and separated via centrifugation. The F-PAA-C 60 precipitate was dried overnight at $80^{\circ} \mathrm{C}$ in an oven under air and then collected.

\section{Gravimetric determination of PAA content}

The content of PAA in the methanolic solution resulted from dialysis was determined gravimetrically. A thermogravimetric analyser (TA Instruments SDT Q600) was used to heat the sample above methanol boiling point, i.e. $70{ }^{\circ} \mathrm{C}\left(1{ }^{\circ} \mathrm{C} / \mathrm{min}\right)$, under Argon atmosphere and weigh the residual PAA.

\section{CHN elemental analysis}

A vario MICRO cube instrument in CHN mode was used for elemental analysis. The samples were initially heated at $110^{\circ} \mathrm{C}$ under vacuum to desorb the pre-adsorbed species and then loaded in tin boats. Linear calibrations obtained with acetanilide standard were used for all elements. A ceramic ash crucible/finger was placed into the combustion tube for the analysis of the fluorinated samples.

\section{SEM/EDX}

Scanning electron microscopy images were taken using SEM Bench-top TM3030 (Hitachi HighTechnology Corporation, Japan). Energy dispersive X-ray spectroscopy was performed using AztecOne system (Oxford Instruments, UK) attached to the SEM, with an accelerating voltage of $5 \mathrm{kV}$ and a count number of 50,000. 


\section{Gravimetric $\mathrm{CO}_{2}$ uptake}

A TA Instruments SDT Q600 Thermogravimetric Analysis/Differential Scanning Calorimetry (TGA/DSC) was used for dynamic $\mathrm{CO}_{2}$ uptake measurements. Capture tests were carried out at atmospheric pressure. Pure $\mathrm{CO}_{2}\left(99.99 \%\right.$ ), $10 \% \mathrm{CO}_{2}$ (equilibrated in $\mathrm{N}_{2}$ ) and $400 \mathrm{ppm} \mathrm{CO}_{2}$ (equilibrated in $\mathrm{N}_{2}$ ) were used for sorption runs, while pure $\operatorname{Ar}(99.995 \%)$ was used as purging gas for samples activation. In a typical run, 5-8 mg of the sample was loaded in an aluminium sample pan and treated at $90{ }^{\circ} \mathrm{C}$ under Ar atmosphere $\left(100 \mathrm{~mL} \mathrm{~min}^{-1}\right)$ to remove all the pre-adsorbed species. The temperature was subsequently set to sorption temperature, and the gas was then switched to either pure $\mathrm{CO}_{2}$ or $10 \% \mathrm{CO}_{2}$ or $400 \mathrm{ppm} \mathrm{CO}_{2}\left(95 \mathrm{~mL} \mathrm{~min}^{-1}\right)$ and held at that temperature until equilibrium $(\mathrm{wt} . \% / \mathrm{min}<0.05)$. The $\mathrm{CO}_{2}$ uptake was estimated from the mass gain in the sorption process.

\section{Volumetric $\mathrm{CO}_{2}$ uptake}

$\mathrm{CO}_{2}$ adsorption isotherms were collected on a Quantachrome iSorbHP1 at 25 and $90{ }^{\circ} \mathrm{C}$, and up to 5 bar, using approximately $70 \mathrm{mg}$ of the sample. Prior to analysis, the samples were degassed under vacuum on the instrument for $6 \mathrm{~h}$ at $90{ }^{\circ} \mathrm{C}$. A sorption rate limit of $0.1 \mathrm{mbar} / \mathrm{min}$ was set at each pressure point as equilibrium setting.

\section{Simultaneous volumetric $\mathrm{CO}_{2}$ adsorption and microcalorimetry}

$\mathrm{CO}_{2}$ adsorption capacities and heats of adsorption were measured using a combined calorimetric-volumetric adsorption apparatus consisting of a Tian-Calvet calorimeter. In a typical experiment, $50 \mathrm{mg}$ of the pelletized $(1000 \mathrm{psi}, 150-250 \mu \mathrm{m})$ sorbent was inserted into one side of the two-pronged sample cell, the other being left empty as a reference. The cell is encased in an aluminium block with highly sensitive thermopiles. The sample was pretreated at $90{ }^{\circ} \mathrm{C}$ for $3 \mathrm{~h}$ under $15 \mathrm{~Pa}$ of a vacuum before setting to the sorption temperature (30 and $90{ }^{\circ} \mathrm{C}$ ) and initiating 
the sorption process. Two pressure transducers connected to the cell and reservoir areas, which were maintained at $30{ }^{\circ} \mathrm{C}$ with heating tape, were used to measure the $\mathrm{CO}_{2}$ uptake. The amount of adsorbed $\mathrm{CO}_{2}$ was calculated using a mole balance with initial and final pressure values from the

cell and reservoir. Heats of $\mathrm{CO}_{2}$ adsorption were simultaneously recorded while the dosed $\mathrm{CO}_{2}$ was being adsorbed. When the cell pressure change was less than $0.01 \mathrm{~Pa} / \mathrm{min}$, the system was assumed to have reached pseudo equilibrium, signifying the end of the collection for that data point. The $\mathrm{CO}_{2}$ pressure was incrementally increased to simultaneously generate an adsorption isotherm and calculate the heat of adsorption. Thus, the reported heats of adsorption are for the incremental amount of $\mathrm{CO}_{2}$ adsorbed and not an average over all $\mathrm{CO}_{2}$ adsorbed.

\section{In-situ transmission FTIR spectroscopy}

In-situ transmission FTIR spectroscopy: Each sample was pressed into a circular self-supported wafer ( $2 \mathrm{~cm}$ in diameter) and loaded into a sample holder. The in-situ IR cell was assembled together with the cell body, sample holder, $\mathrm{SrF}_{2} \mathrm{IR}$ windows, and heating block. The assembled in situ IR cell was inserted into a Nicolet 8700 FTIR spectrometer. The sample was activated at 90 ${ }^{\circ} \mathrm{C}$ for $3 \mathrm{~h}$ under helium flow $(80 \mathrm{~mL} / \mathrm{min})$ and cooled to $30^{\circ} \mathrm{C}$, and then a background spectrum was collected before the $\mathrm{CO}_{2}$ adsorption. All in-situ IR spectra of the material during $\mathrm{CO}_{2}$ adsorption were collected against the background spectrum of the activated sorbents, including the contribution of the cell. Subsequently, the flow was switched from helium to a $\mathrm{CO}_{2}$ gas stream for $1 \mathrm{~h}$. During this period, a spectrum was recorded every minute. Each spectrum was collected with 32 scans at a resolution of $4 \mathrm{~cm}^{-1}$. After each experiment, a circular stamp (6.35 $\mathrm{mm}$ in diameter) was used to cut the wafer, and it was weighed to determine its density. All spectra were normalized by the density of the wafer. 


\section{PALS Analysis}

A digital positron lifetime spectrometer manufactured by TechnoAP with two photomultipliers: $\mathrm{H} 3378-50$ each one coupled with a single crystal of $\mathrm{BaF}_{2}$ scintillators was used in the current studies. The time resolution (full width half maximum, FWHM) of the instrument was about 190 ps. The positron source used in our experiment was a ${ }^{22} \mathrm{NaCl}$-solution evaporated on a $7 \mu \mathrm{m}$ thick Kapton foil with an activity of about $20 \mu \mathrm{Ci}$. More than $10^{6}$ counts were collected for each positron

lifetime spectrum. All spectra were deconvoluted using LT code, ${ }^{[43]}$ the background and source correction was included.

\section{Supporting Information}

Supporting Information is available on ChemRxiv.

\section{Acknowledgments}

Financial support was provided by the Reduce Industrial Carbon Emissions (RICE) and Flexible Integrated Energy Systems (FLEXIS) research operations part funded by the EU's European Regional Development Fund through the Welsh Government. Funding for the work of CJY, JJL and CWJ was provided in part by UNCAGE-ME, an Energy Frontier Research Center funded by the U.S. Department of Energy, Office of Science, Basic Energy Sciences under award no. DESC0012577. MT wish to acknowledge funding from the European Union's Horizon 2020 research and innovation programme under the Marie Skłodowska-Curie grant agreement No 663830. JMUK wish to acknowledge the project 18A12-210FP of the INL Laboratory Directed Research \& Development (LDRD) program. 


\section{References}

[1] https://www.esrl.noaa.gov/gmd/ccgg/trends/mlo.html, accessed: 14 December 2020.

[2] T. Covert, M. Greenstone, C. R. Knittel, J. Econ. Perspect. 2016, 30, 117.

[3] a) G. T. Rochelle, Science 2009, 325, 1652; b) G. T. Rochelle, in Absorption-Based Postcombustion Capture of Carbon Dioxide, DOI: https://doi.org/10.1016/B978-0-08-1005149.00003-2 (Ed: P. H. M. Feron), Woodhead Publishing 2016, p. 35.

[4] A. B. Rao, E. S. Rubin, Environ. Sci. Technol. 2002, 36, 4467.

[5] a) E. S. Sanz-Pérez, C. R. Murdock, S. A. Didas, C. W. Jones, Chem. Rev. 2016, 116, 11840; b) E. National Academies of Sciences, Medicine, Negative Emissions Technologies and Reliable Sequestration: A Research Agenda, The National Academies Press, Washington, DC 2019.

[6] H. A. Patel, J. Byun, C. T. Yavuz, ChemSusChem 2017, 10, 1303.

[7] M. Bui, C. S. Adjiman, A. Bardow, E. J. Anthony, A. Boston, S. Brown, P. S. Fennell, S. Fuss, A. Galindo, L. A. Hackett, J. P. Hallett, H. J. Herzog, G. Jackson, J. Kemper, S. Krevor, G. C. Maitland, M. Matuszewski, I. S. Metcalfe, C. Petit, G. Puxty, J. Reimer, D. M. Reiner, E. S. Rubin, S. A. Scott, N. Shah, B. Smit, J. P. M. Trusler, P. Webley, J. Wilcox, N. Mac Dowell, Energy Environ. Sci. 2018, $11,1062$.

[8] a) M. Oschatz, M. Antonietti, Energy Environ. Sci. 2018, 11, 57; b) S. A. Didas, S. Choi, W. Chaikittisilp, C. W. Jones, Acc. Chem. Res. 2015, 48, 2680.

[9] a) J. Yu, Y. Zhai, S. S. C. Chuang, Ind. Eng. Chem. Res. 2018, 57, 4052; b) A. Koutsianos, A. R. Barron, E. Andreoli, J. Phys. Chem. C 2017, 121, 21772; c) L. B. Hamdy, R. J. Wakeham, M. Taddei, A. R. Barron, E. Andreoli, Chem. Mater. 2019, 31, 4673.

[10] a) X. Xu, C. Song, J. M. Andresen, B. G. Miller, A. W. Scaroni, Energy Fuels 2002, 16, 1463; b) X. $\mathrm{Xu}, \mathrm{C}$. Song, J. M. Andrésen, B. G. Miller, A. W. Scaroni, Microporous Mesoporous Mater. 2003, 62, 29; c) R. S. Franchi, P. J. E. Harlick, A. Sayari, Ind. Eng. Chem. Res. 2005, 44, 8007; d) G. P. Knowles, J. V. Graham, S. W. Delaney, A. L. Chaffee, Fuel Process. Technol. 2005, 86, 1435.

[11] T. L. Donaldson, Y. N. Nguyen, Ind. Eng. Chem. Fundam. 1980, 19, 260.

[12] W. Xie, M. Yu, R. Wang, Aerosol. Air. Qual. Res. 2017, 17, 2715.

[13] E. Andreoli, L. Cullum, A. R. Barron, Ind. Eng. Chem. Res. 2015, 54, 878.

[14] a) X. Feng, G. Hu, X. Hu, G. Xie, Y. Xie, J. Lu, M. Luo, Ind. Eng. Chem. Res. 2013, 52, 4221; b) A. Heydari-Gorji, Y. Yang, A. Sayari, Energy Fuels 2011, 25, 4206; c) M. Jahandar Lashaki, A. Sayari, Chem. Eng. J. 2018, 334, 1260; d) R. Kishor, A. K. Ghoshal, Ind. Eng. Chem. Res. 2017, 56, 6078; e) L. Wang, M. Yao, X. Hu, G. Hu, J. Lu, M. Luo, M. Fan, Appl. Surf. Sci. 2015, 324, 286; f) X. Yan, L. Zhang, Y. Zhang, G. Yang, Z. Yan, Ind. Eng. Chem. Res. 2011, 50, 3220; g) H. Zhang, A. Goeppert, S. Kar, G. K. S. Prakash, J. CO2 Util. 2018, 26, 246.

[15] H. T. Kwon, M. A. Sakwa-Novak, S. H. Pang, A. R. Sujan, E. W. Ping, C. W. Jones, Chem. Mater. 2019, 31, 5229.

[16] a) Y. Kuwahara, D.-Y. Kang, J. R. Copeland, N. A. Brunelli, S. A. Didas, P. Bollini, C. Sievers, T. Kamegawa, H. Yamashita, C. W. Jones, J. Am. Chem. Soc. 2012, 134, 10757; b) J. Liu, D. Cheng, Y. Liu, Z. Wu, Energy Fuels 2013, 27, 5416; c) A. A. Rownaghi, A. Kant, X. Li, H. Thakkar, A. Hajari, Y. He, P. J. Brennan, H. Hosseini, W. J. Koros, F. Rezaei, ChemSusChem 2016, 9, 1166; d) M. A. Sakwa-Novak, A. Holewinski, C. B. Hoyt, C.-J. Yoo, S.-H. Chai, S. Dai, C. W. Jones, Langmuir 2015, 31, 9356.

[17] M. E. Potter, K. M. Cho, J. J. Lee, C. W. Jones, ChemSusChem 2017, 10, 2192.

[18] A. Holewinski, M. A. Sakwa-Novak, C. W. Jones, J. Am. Chem. Soc. 2015, 137, 11749.

[19] a) A. Heydari-Gorji, Y. Belmabkhout, A. Sayari, Langmuir 2011, 27, 12411; b) A. Sayari, Q. Liu, P. Mishra, ChemSusChem 2016, 9, 2796.

[20] E. Andreoli , A. R. Barron ChemSusChem 2015, 8, 2635. 
[21] P. Sharma, S. Chakrabarty, S. Roy, R. Kumar, Langmuir 2018, 34, 5138.

[22] a) M. A. Sakwa-Novak, S. Tan, C. W. Jones, ACS Appl. Mater. Interfaces 2015, 7, 24748; b) J. Wang, D. Long, H. Zhou, Q. Chen, X. Liu, L. Ling, Energy Environ. Sci. 2012, 5, 5742; c) J. Wang, M. Wang, B. Zhao, W. Qiao, D. Long, L. Ling, Ind. Eng. Chem. Res. 2013, 52, 5437.

[23] A. Goeppert, H. Zhang, R. Sen, H. Dang, G. K. S. Prakash, ChemSusChem 2019, 12, 1712.

[24] D. A. Long, J. Raman Spectrosc. 2004, 35, 905.

[25] E. Andreoli, E. P. Dillon, L. Cullum, L. B. Alemany, A. R. Barron, Sci. Rep. 2014, 4, 7304.

[26] M. Caplow, J. Am. Chem. Soc. 1968, 90, 6795.

[27] S. J. Park, J. J. Lee, C. B. Hoyt, D. R. Kumar, C. W. Jones, Adsorption 2020, 26, 89.

[28] C. Gebald, J. A. Wurzbacher, P. Tingaut, T. Zimmermann, A. Steinfeld, Environ. Sci. Technol. 2011, 45, 9101.

[29] L. Wang, R. T. Yang, J. Phys. Chem. C 2011, 115, 21264.

[30] M. E. Potter, S. H. Pang, C. W. Jones, Langmuir 2017, 33, 117.

[31] a) M. A. Alkhabbaz, P. Bollini, G. S. Foo, C. Sievers, C. W. Jones, J. Am. Chem. Soc. 2014, 136, 13170; b) S. A. Didas, A. R. Kulkarni, D. S. Sholl, C. W. Jones, ChemSusChem 2012, 5, 2058.

[32] A. Samanta, A. Zhao, G. K. H. Shimizu, P. Sarkar, R. Gupta, Ind. Eng. Chem. Res. 2012, 51, 1438.

[33] M. R. Mello, D. Phanon, G. Q. Silveira, P. L. Llewellyn, C. M. Ronconi, Microporous Mesoporous Mater. 2011, 143, 174.

[34] S. J. Thompson, M. Soukri, M. Lail, Chem. Eng. J. 2018, 350, 1056.

[35] Y. Belmabkhout, A. Sayari, Adsorption 2009, 15, 318.

[36] R. Serna-Guerrero, Y. Belmabkhout, A. Sayari, Chem. Eng. J. 2010, 161, 173.

[37] a) Z. Bacsik, N. Ahlsten, A. Ziadi, G. Zhao, A. E. Garcia-Bennett, B. Martín-Matute, N. Hedin, Langmuir 2011, 27, 11118; b) G. S. Foo, J. J. Lee, C.-H. Chen, S. E. Hayes, C. Sievers, C. W. Jones, ChemSusChem 2017, 10, 266.

[38] C.-J. Yoo, L.-C. Lee, C. W. Jones, Langmuir 2015, 31, 13350.

[39] a) G. Consolati, F. Quasso, in Polymer Physics, DOI: 10.1002/9780470600160.ch10 (Eds: L. A. Utracki, A. M. Jamieson) 2010, p. 391; b) G. Dlubek, in Polymer Physics, DOI: 10.1002/9780470600160.ch11 (Eds: L. A. Utracki, A. M. Jamieson) 2010, p. 421.

[40] a) S. J. Tao, The Journal of Chemical Physics 1972, 56, 5499; b) M. Eldrup, D. Lightbody, J. N. Sherwood, Chem. Phys. 1981, 63, 51.

[41] Q. Song, S. K. Nataraj, M. V. Roussenova, J. C. Tan, D. J. Hughes, W. Li, P. Bourgoin, M. A. Alam, A. K. Cheetham, S. A. Al-Muhtaseb, E. Sivaniah, Energy Environ. Sci. 2012, 5, 8359.

[42] a) K. Tanaka, T. Kawai, H. Kita, K.-i. Okamoto, Y. Ito, Macromolecules 2000, 33, 5513; b) A. Shimazu, T. Miyazaki, S. Katayama, Y. Ito, J. Polym. Sci., Part B: Polym. Phys. 2003, 41, 308; c) J. Kruse, J. Kanzow, K. Rätzke, F. Faupel, M. Heuchel, J. Frahn, D. Hofmann, Macromolecules 2005, 38, 9638.

[43] J. Kansy, LT programs, http://prac.us.edu.pl/kansy/index.php?id¹/4t10, accessed: 16 November 2010. 